\title{
Quiste hidatídico renal
}

\section{Hydatid renal cyst}

\author{
Walter Guitton Arteaga ${ }^{1, a}$, Emanuel Millones-Sánchez ${ }^{1, b}$, Gabriela López Córdova ${ }^{1, c}$ \\ ${ }^{1}$ Departamento de Anatomía Patológica, Hospital Nacional Arzobispo Loayza. Lima, Perú. \\ a Médico anatomopatólogo, ORCID: 0000-0003-2993-2840 \\ ${ }^{\mathrm{b}}$ Médico residente de anatomía patológica, ORCID: 0000-0001-9729-5041 \\ ${ }^{\text {c}}$ Médico residente de anatomía patológica, ORCID: 0000-0001-5575-3729
}

An Fac med. 2021;82(1):62-5. / DOI: https://doi.org/10.15381/anales.v82i1.19861

\section{Correspondencia:}

Emanuel Millones Sánchez

apmillones@gmail.com

Recibido: 12 de marzo 2021

Aprobado: 27 de abril 2021

Publicación en línea: 5 de mayo 2021

Conflictos de interés: Los autores

declaran no tener conflictos de interés.

Fuente de financiamiento:

Autofinanciado

Citar como: Guitton W, Millones-Sánchez E, López G. Quiste hidatídico renal. An Fac med. 2021;82(1):62-5. DOI: https:/ doi.org/10.15381/anales.v82i1.19861

\section{Resumen}

La hidatidosis es una parasitosis producida por larvas de Echinococcus, las cuales forman quistes frecuentemente localizados en hígado y pulmón; la localización renal sólo ha sido reportada en el $4 \%$ de formas viscerales. Presentamos el caso de un varón de 19 años procedente de la sierra de Lima, el cual acude a nuestro hospital con dolor en flanco izquierdo y hematuria, se le realizó una tomografía sugerente de quiste simple complicado. Se le realizó nefrectomía y se envió la pieza al servicio de anatomía patológica, en el cual observó formación quística en cuyo interior se encontraron múltiples membranas blanquecinas plegadas. En el examen microscópico se observaron membranas anhistas, consistente con quiste hidatídico renal.

Palabras clave: Equinococosis; Riñón; Enfermedades Renales Quisticas; Enfermedades Parasitarias (fuente: DeCS BIREME).

\section{Abstract}

Hydatidosis is a parasitosis produced by Echinococcus larvae, which form cysts frequently located in the liver and lung; Renal location has only been reported in $4 \%$ of visceral forms. We present the case of a 19-year-old man from Lima, who came to our hospital with pain in the left flank and hematuria, a tomography was performed suggestive of complicated simple cyst. A nephrectomy is performed and the piece is sent to the Pathology Department, in which they observe cystic formation inside which multiple folded whitish membranes are observed: in the microscopic examination anhistic membranes are observed, consistent with a renal hydatid cyst.

Keywords: Echinococcosis; Kidney; Cystic Kidney Diseases; Parasitic Diseases (source: MeSH NLM). 


\section{INTRODUCCIÓN}

La hidatidosis es una parasitosis producida por larvas de Echinococcus, en cuyo ciclo de vida el ser humano es un huésped accidental, tras consumir alimentos contaminados. Es endémica de zonas rurales de países en vías de desarrollo. Las larvas forman quistes que ocupan espacio y dan lugar a lesiones por compresión. Estos quistes pueden comprometer virtualmente cualquier víscera del organismo, siendo los lugares más frecuentes el hígado y el pulmón ${ }^{(1)}$. El diagnóstico clínico es difícil debido a la similitud con otras enfermedades que ocupan espacio. Se requiere evaluación por imágenes y pruebas inmunológicas que apoyen la sospecha diagnóstica. La confirmación de la infección se realiza por observación directa de los quistes en macroscopía y/o el examen microscópico en el que se observan estructuras del quiste y protoescólices o ganchos ${ }^{(2)}$.

Dentro de los países que conforman el Proyecto Subregional de Vigilancia y Control de la Equinococosis Quística, el Perú mostro mayor numero de casos en el periodo 2009-2014, con 20785 pacientes ${ }^{(3)}$. Sin embargo, solo se ha presentado un caso de hidatidosis renal, asociada a glomeruloesclerosis focal y segmentaria ${ }^{(4)}$.

Presentamos el caso de un paciente varón joven en el que el quiste hidatídico se presentó en riñón izquierdo, una ubicación inusual ${ }^{(5)}$.

\section{REPORTE DE CASO}

Paciente varón, de 19 años, natural y procedente de Huarochirí (sierra de Lima) y de ocupación agricultor, sin antecedentes de importancia, acudió a nuestro hospital con un tiempo de enfermedad de año y medio, caracterizado por dolor tipo cólico en flanco izquierdo, de intensidad moderada; asimismo, hematuria autolimitada o que cedió con antiinflamatorios no esteroideos. Al examen físico, se palpó a nivel de flanco izquierdo tumoración móvil de $8 \times 6 \mathrm{~cm}$. El resto del examen no fue contributorio. En los exámenes auxiliares, solo destacó un leve aumento de proteínas totales $8,85 \mathrm{~g} / \mathrm{dL}$ (VN: 6,5-8,3) a predominio de globulinas $4,11 \mathrm{~g} / \mathrm{dL}(2,5-3)$.
Se realizó tomografía de vías urinarias y tomografía toraco-abdominal, que informó en riñón izquierdo imagen quística, de márgenes definidos, contenido heterogéneo, reticular y en láminas, que sugirió quiste simple complicado y hemorrágico en vías de resolución. No se identificaron lesiones quísticas pulmonares ni hepáticas (Figura 1). Con el diagnóstico presuntivo de tumor renal de etiología a

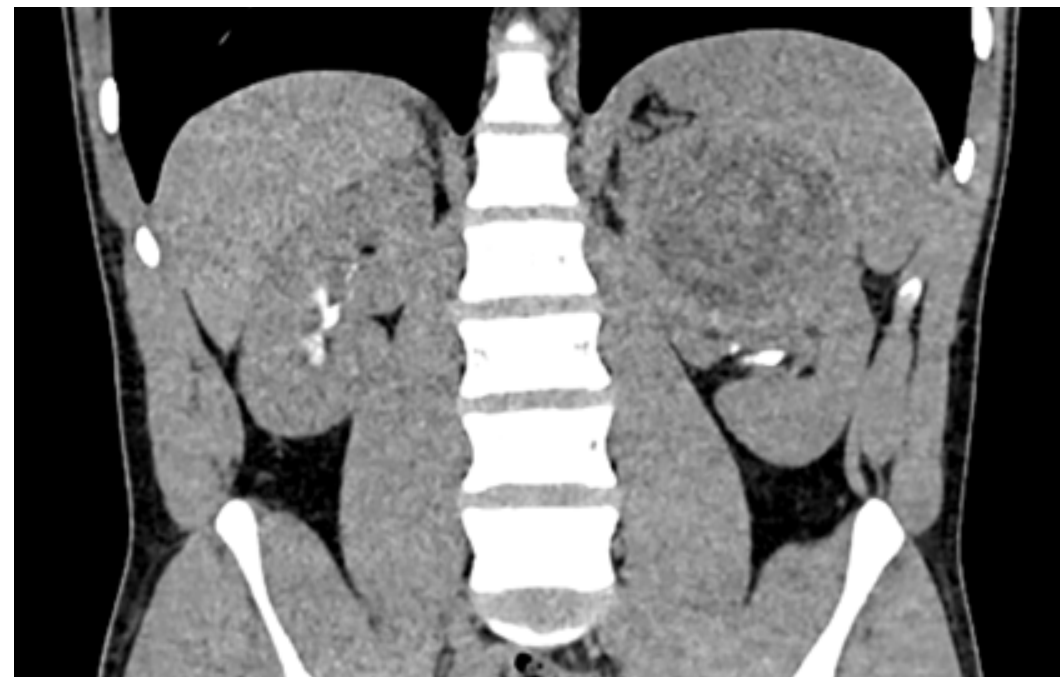

Figura 1. UROTEM: Quiste complejo en riñón izquierdo.

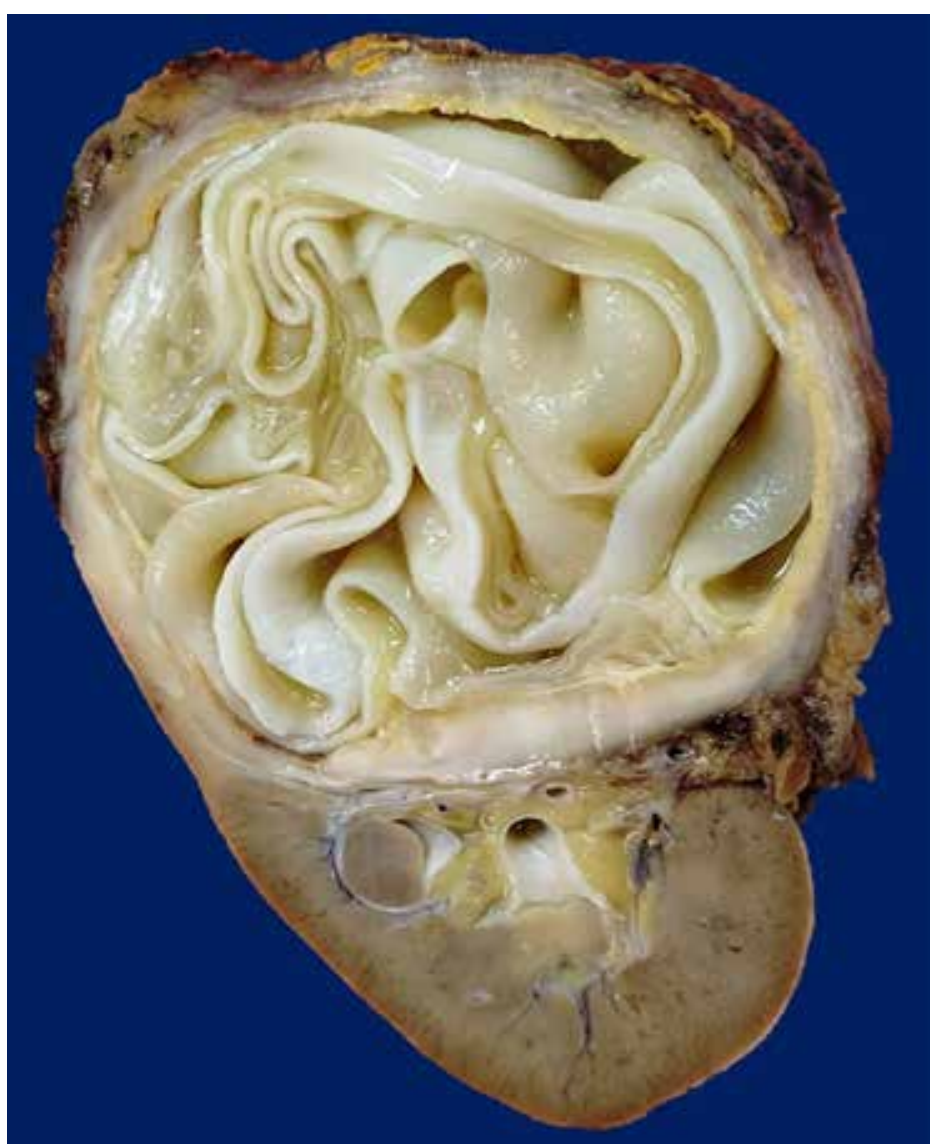

Figura 2. Corte macroscópico de quiste renal complejo. 
determinar, se realizó nefrectomía total izquierda la cual transcurrió sin complicaciones.

En anatomía patológica se recibió el producto de nefrectomía izquierda, que midió $13 \times 9 \times 7 \mathrm{~cm}$ y pesó $498 \mathrm{~g}$, el riñón se encontró parcialmente cubierto por tejido adiposo en el que se encontraba la glándula suprarrenal $(5 \times 2 \times 1,5 \mathrm{~cm})$. Se identificó gran formación nodular, de consistencia firme, que midió $9 \times 7,5 \times 7 \mathrm{~cm}$ en polo superior y tercio medio. Al corte, la lesión identificada correspondió a una formación quística, con grosor de pared de 0,6 cm, en cuyo interior se observaron múltiples membranas blanquecinas plegadas. Dicho quiste desplazaba todo el sistema pielocalicial (Figura 2).

En el análisis microscópico, se identificó reacción inflamatoria intensa en la pared del quiste, con células gigantes multinucleadas y fibrosis, que correspondía a la capa adventicia (Figura 3). En el contenido, se observó láminas eosinófilas claras acelulares (membranas anhistas), y adyacente a ellas, una capa celular eosinófila intensa (capa germinativa) (Figura 4).

Con dichos hallazgos, se informó el diagnóstico de quiste hidatídico renal izquierdo, con reacción inflamatoria y fi- brosis periquística. El parénquima renal restante se encontró fibrosado y con tiroidización tubular focal, así como glándula suprarrenal sin alteraciones significativas. Tras informar al servicio de urología, se realizó prueba ELISA anti Echinococcus sp, IgG: 3,09 mg/dL (positivo > 1,1). El paciente se encuentra estable y recibiendo tratamiento específico al término del presente reporte.

\section{DISCUSIÓN}

El quiste hidatídico es usualmente reportado en hígado y en pulmón, es raramente localizado en bazo, esqueleto, riñón, cerebro, músculo cardiaco, peritoneo y tejido celular subcutáneo ${ }^{(6)}$. La localización renal de un quiste hidatídico es infrecuente, se reporta solo en $4 \%$ de las formas viscerales; sin embargo, es la ubicación más común del tracto urogenital ${ }^{(5)}$. En los pocos casos presentados, generalmente es primario, único y de ubicación preferentemente polar. Como en nuestro paciente, el riñón izquierdo es el más común en afectarse, sin tener una explicación clara de dicho fenómeno ${ }^{(7)}$.

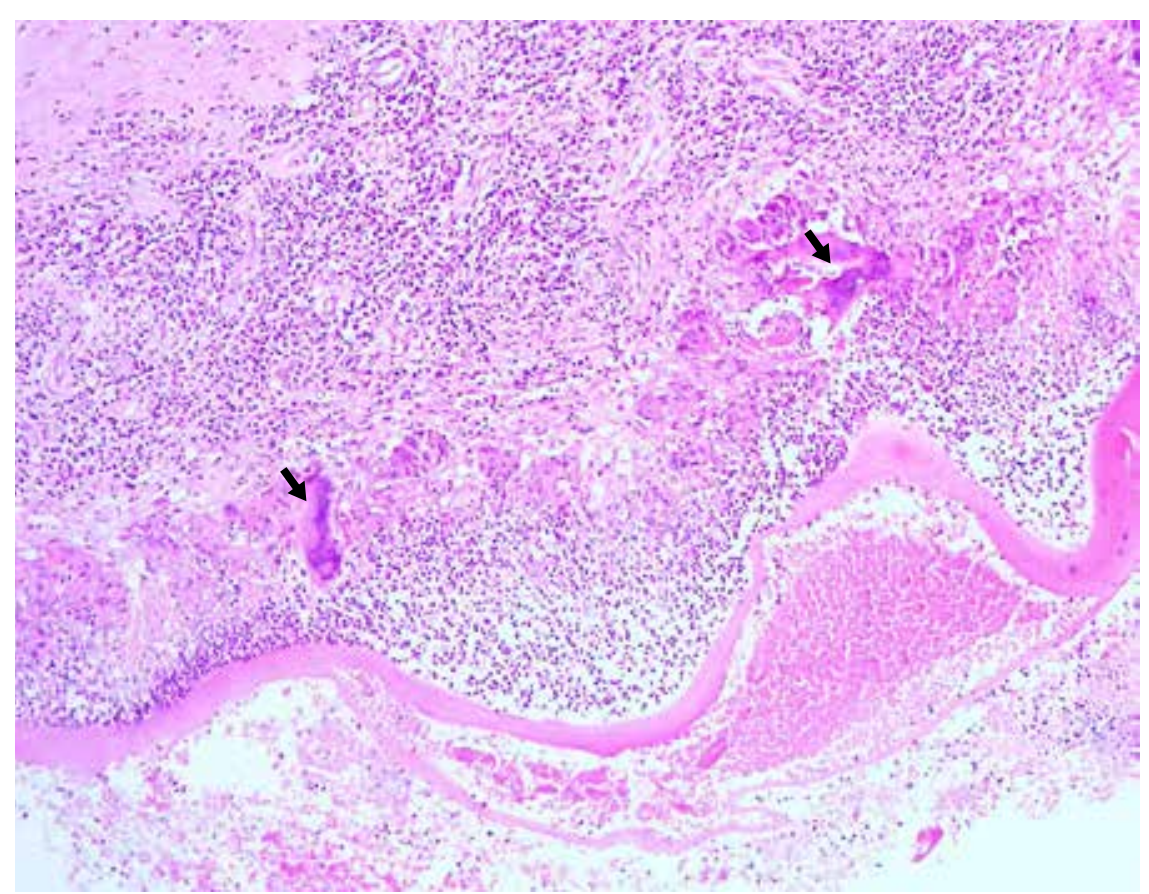

Figura 3. Corte microscópico de pared de quiste. Se observa una reacción inflamatoria intensa, células gigantes multinucleadas (flechas) y fibrosis. Tinción de hematoxilina - eosina, 20x.
El cuadro clínico no es específico, pudiendo ser asintomático por muchos años y descubriéndose de forma accidental tras exámenes de imagen por otra causa ${ }^{(5)}$. Cuando se producen síntomas, se pueden identificar 2 escenarios, quiste cerrado (el de nuestro paciente), con lumbalgia, hematuria y masa palpable ${ }^{(8)}$; y quiste abierto, que viene acompañado de lumbalgia súbita e intensa, hidatiduria marcada (signo patognomónico pero muy raro) y reacción anafiláctica ${ }^{(9)}$. Las complicaciones en las localizaciones usuales tanto como en las inusuales son similares ${ }^{(10)}$.

Los exámenes de laboratorio no son específicos, se presenta eosinofilia entre el $20 \%$ y $50 \%$ de los casos ${ }^{(5)}$. Son las pruebas de imágenes las que orientan el diagnóstico, principalmente la ecografía (40\% - 70\%) y tomografía computarizada ${ }^{(11)}$. Al igual que en el quiste hidatídico hepático, se pueden emplear la clasificación de Garbhi ${ }^{(12)}$ y la de la OMS ${ }^{(13)}$, siendo la más actual y aceptada esta última. En nuestro caso, la tomografía podría orientar al diagnostico, al evidenciar quistes con estructuras internas a modo de láminas.

El tratamiento de estos casos es principalmente quirúrgico, intentando preservar la mayor cantidad de tejido renal posible. Dado el tamaño del quiste en nuestro paciente, se decidió la nefrectomía total, similar a otros casos reportados ${ }^{(11)}$. Se puede intentar el drenaje percutáneo, pero este procedimiento se reserva para quistes pequeños ${ }^{(10)}$. Nuestro paciente presentó una evolución satisfactoria tras la cirugía y recibió tratamiento médico (mebendazol) posterior a la misma.

A modo de conclusión, el quiste hidatídico renal es una entidad infrecuente, que puede ser sospechada en casos de masa quística en pacientes de zonas endémicas. La hidatiduria es patognomónica; sin embargo, es un hallazgo excepcional. Su tratamiento es quirúrgico de primera intención, reservándose procedimientos menos invasivos para quistes pequeños. El tratamiento médico se considera insuficiente por sí mismo, pudiendo ser adyuvante.

\section{AGRADECIMIENTOS}

A los servicios de urología y radiología del Hospital Nacional Arzobispo Loayza, 


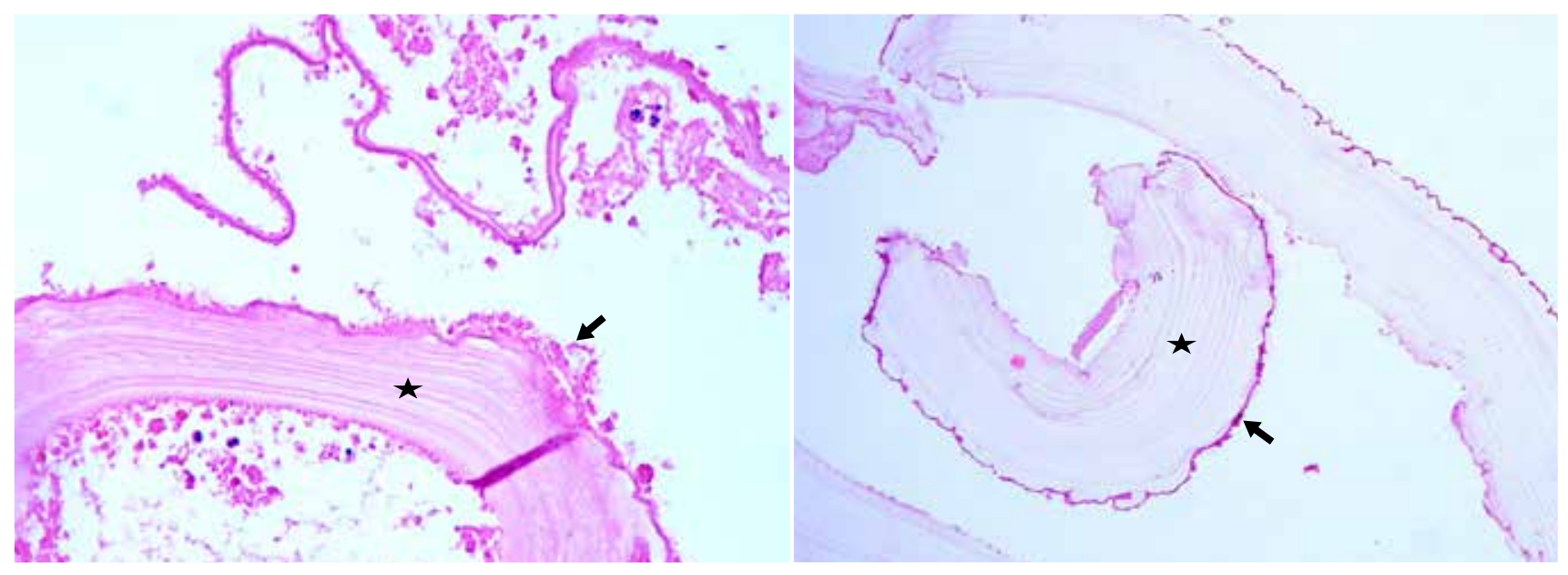

Figura 4. Cortes microscópicos del contenido del quiste. Se identifican membranas anhistas (estrellas) y capa germinativa (flechas). Tinción de hematoxilina - eosina, 20x.

por su apoyo en la recolección de datos de la historia clínica y reportes de estudios por imágenes.

\section{REFERENCIAS BILIOGRÁFICAS}

1. David Botero, Marcos Restrepo. Parasitosis humanas. 5ta edición. Medellín: Corporación para investigaciones biológicas. 2012.

2. Kern P, da Silva AM, Akhan O, Müllhaupt B, Vizcaychipi KA, Budke C, et al. The echinococcoses: diagnosis, clinical management and burden of disease. Advances in Parasitology. 2017;96: 259369. DOI: 10.1016/bs.apar.2016.09.006

3. Pavletic CF, Larrieu E, Guarnera EA, Casas N, Irabedra P, Ferreira C, et al. Cystic echinococcosis in South America: a call for action. Rev Panam Salud Publica. 2017;41:e42. DOI: 10.26633/ RPSP.2017.42
4. Vizcarra C, Peña $C$, del Carpio $H$, Chávez E, Gónzalez-Polar J, Asato C. Hidatidosis renal y glomeruloesclerosis focal y segmentaria: un raro caso presentado como tumor renal en Perú. NefroPlus. 2018;10(1):85-88

5. Zmerli S, Ayed M, Horchani A, Chami I, El Ouakdi M, Ben Slama MR. Hydatid cyst of the kidney: diagnosis and treatment. World J Surg. 2001;25:68-74 DOI: $10.1007 / \mathrm{s} 002680020009$

6. Salamone G, Licari L, Randisi B, Falco N, Tutino R, Vaglica A, et al. Uncommon localizations of hydatid cyst. Review of the literature. G Chir. 2016;37(4):180-185. DOI: 10.11138/ gchir/2016.37.4.180

7. Ketata H, Peyromaure M. Quiste hidatídico renal EMC - Urología. 2005;37(2):1-6. DOI: https://doi. org/10.1016/S1761-3310(05)43428-3

8. Fekak H, Bennani S, Rabii R, Mezzour MH Debbagh A, El Mrini M, et al. Kyste hydatique du rein : à propos de 90 cas. Ann Urol (Paris). 2003;37:85-9. DOI: 10.5489/cuaj.1374
9. Unsal A, Cimentepe E, DilmenA, Yenidunya S, Saglam R. An unusual cause of renal colic: hydaturia. IntJUrol. 2001;8:319-21. DOI: https://doi. org/10.1046/j.1442-2042.2001.00307.x

10. Kabaalioglu A, Karaali K, Apaydin A, Melikoglu $M$, Sindel T, Lüleci E. Ultrasound-guided percutaneous sclerotherapy of hydatid liver cysts in children. Pediatr Surg Int. 2000;16:346-50. DOI: 10.1007/s003830000356

11. Ameur A, Lezrek M, Boumdin H, Touiti D, Abbar M, Beddouch A. Le kyste hydatique du rein. Traitement à propos de 34 cas. Prog Urol. 2002;12: 409-14.

12. Gharbi HA, Hassine W, Braumer MW. Ultrasound examination of the hydatic liver. Radiology. 1981;139: 459-463.

13. WHO Informal Working Group. International classification of ultrasound images in cystic echinococcosis for application in clinical and field epidemiological settings. Acta Trópica. 2003; 85: 253-261. 